\title{
Imported Dogs as Possible Vehicles of Vibrio Cholerae 01 Causing Cholera Outbreaks in Northern Vietnam
}

\author{
Tuan Cuong Ngo ${ }^{1}$, Dong Tu Nguyen ${ }^{1,2}$, Huy Hoang Tran ${ }^{1}$, Thanh Huong Le ${ }^{1}$, Hoai Thu Nguyen ${ }^{1}$, \\ Tai The Diep ${ }^{3}$, Thi Phuong Lan Nguyen ${ }^{3}$, Binh Minh Nguyen ${ }^{1}$, Nhu DuongTran ${ }^{4}$, Tetsu Yamashiro ${ }^{5}$, \\ Kouichi Morita ${ }^{2}$, Tran Hien Nguyen ${ }^{4}$ and Masahiko Ehara ${ }^{*}, 6$
}

\author{
${ }^{I}$ Department of Bacteriology, National Institute of Hygiene and Epidemiology, No.1 Yersin Street, Hanoi 10, 000, \\ Vietnam \\ ${ }^{2}$ Department of Virology, Institute of Tropical Medicine, Nagasaki University, 1-12-4 Sakamoto, Nagasaki 852-8523, \\ Japan \\ ${ }^{3}$ Department of Microbiology and Immunology, Pasteur Institute, 167 Pasteur Street, 8 Ward, 3 District, Ho Chi Minh \\ City, Vietnam \\ ${ }^{4}$ Department of Epidemiology, National Institute of Hygiene and Epidemiology, No.1 Yersin Street, Hanoi 10, 000, \\ Vietnam \\ ${ }^{5}$ Vietnam Research Station, Institute of Tropical Medicine, Nagasaki University, 1-12-4 Sakamoto, Nagasaki 852-8523, \\ Japan \\ ${ }^{6}$ Department of Bacteriology, Institute of Tropical Medicine, Nagasaki University, 1-12-4 Sakamoto, Nagasaki 852- \\ 8523, Japan
}

\begin{abstract}
Strains of $V$. cholerae O1 were isolated from the sewage and a pond near the first patient's house and also from domestic vegetables obtained at a neighboring market. From 24 October 2007 to 25 June 2009, 1,505 cases were confirmed positive for $V$. cholerae O1 (biotype El Tor, serotype Ogawa) in 22 cities and provinces in northern Vietnam. On May 8 and May 12, 2009, epidemic strains of $V$. cholerae O1 were isolated from dogs in slaughter houses in Hanoi and from dogs in cages in Thanh Hoa, respectively. Isolates of $V$. cholerae $\mathrm{O} 1$ in Laos and Thailand were found to be the same clone as those isolates from dogs, patients and environmental water samples in northern Vietnam. Although the transmission routes of cholera differed between the northern and southern provinces of Vietnam, the same clonality was observed among isolates from 2007 to 2010.
\end{abstract}

Keywords: Cholera, clonality, multiple drug resistance gene, tetA (class D).

\section{INTRODUCTION}

Cholera is a form of acute diarrhea caused by Vibrio cholerae $\mathrm{O} 1$ and O139. People living under poor sanitary conditions are exposed to the threat of cholera infection after consuming contaminated food and water. From 24 October 2007 to 25 June 2009 , there were more than 7,000 cases suffering from acute severe, watery diarrhea in 22 cities and provinces in northern Vietnam. Of these cases, more than 1,500 were culture-positive for $V$. cholerae $\mathrm{O} 1$ when stool samples were tested at the Department of Bacteriology, National Institute of Hygiene and Epidemiology (NIHE), Hanoi. It is noteworthy that most of the cases occurred in northern Vietnam including Hanoi. At the beginning of the outbreak, most of the patients were among those citizens who had taken dog meat at their homes or at dog meat restaurants. There have been several reports of excretion of non-O1 $V$. cholerae (NAG vibrio) by ruminants $[1,2]$ and dogs [3] from hyperendemic areas and the isolation of

Address correspondence to this author at the Department of Bacteriology, Institute of Tropical Medicine, Nagasaki University, 1-12-4 Sakamoto, Nagasaki 852-8523, Japan; Tel: +81 95819 7832; Fax: +81 95819 7805;

E-mail: ehara@nagasaki-u.ac.jp
$V$. cholerae $\mathrm{O} 1$ from household animals from a nonendemic area [4]. However, no reports are available on the role of dogs in the maintenance and transmission of epidemic strains of $V$. cholerae $\mathrm{O} 1$. This communication reports the isolation of epidemic $V$. cholerae $\mathrm{O} 1$ strains with cholera toxin $(c t x)$ gene from dogs and the clonality of epidemic strains isolated in Vietnam, Laos, Thailand. and Cambodia. Multiplex polymerase chain reaction (PCR) and pulsed field gel electrophoresis (PFGE) were used to investigate the genetic characteristics of epidemic strains of $V$. cholerae $\mathrm{O} 1$.

\section{MATERIALS AND METHODS}

\section{Samples for Screening of $V$. cholerae 01}

Sewage and the other Environmental Water

Samples $(500 \mathrm{ml})$ were collected in clean plastic bottles and immediately transported to the laboratory at ambient temperature.

\section{Vegetable}

Vegetables (herbs and raw vegetables) were collected at a market near the patient's house and homogenized with Bag Mixer400 (Interscience, France). 
Dogs

Rectal swabs were taken from dogs in slaughter houses in Hanoi and from dog-houses in Thanh Hoa $(250 \mathrm{~km}$ south of Hanoi) where imported dogs were kept before delivery to slaughter houses in Hanoi. Each rectal swab was kept in a test tube containing $10 \mathrm{ml}$ of alkaline peptone water $(p \mathrm{H} \mathrm{8.6)}$ and transported to the laboratory at ambient temperature.

\section{Knife, Floor, Table, Dog Meat in a Bucket in Dog Slaughter Houses in Hanoi}

Samples were collected from these materials by swabbing the surface with a sterile cotton swab and kept in $10 \mathrm{ml}$ of alkaline peptone water and immediately transported to the laboratory at ambient temperature.

\section{Human Stools}

Rectal swabs were taken from individuals living with a cholera patient and processed in the same way as dog rectal swabs. In hospitals, stool specimens were collected in plastic containers, and then transported to National Institute of Health and Hygiene (NIHE) without delay.

\section{Bacteriological Examination}

\section{Water Samples}

The water sample $(450 \mathrm{ml})$ was mixed with $50 \mathrm{ml}$ of $10 \mathrm{x}$ alkaline peptone water in a $1 \mathrm{~L}$ flask and incubated overnight at $37{ }^{\circ} \mathrm{C}$ without shaking. For enrichment, two successive subcultures were done every 6-8 hr by shaking. One $\mathrm{ml}$ of original culture was transferred to $9 \mathrm{ml}$ of fresh alkaline peptone water. A small aliquot of the culture was plated on thiosulfate-citrate-bile salts-sucrose agar (TCBS, Eiken, Tokyo, Japan) and alkaline agar plate (nutrient agar, $p \mathrm{H} \mathrm{8.6)}$ at each step (primary, secondary and tertiary plating).

\section{Vegetables}

After homogenization, $25 \mathrm{ml}$ of the sample was mixed with $225 \mathrm{ml}$ of alkaline peptone water and incubated overnight at $37^{\circ} \mathrm{C}$. The enrichment method was applied as in the case of water sample.

\section{Swab Specimens}

Swab specimens were incubated overnight at $37^{\circ} \mathrm{C}$ and two successive subcultures for enrichment were performed as above.

Suspected colonies were tested for slide agglutination with $V$. cholerae O1-polyvalent antisera (BIO-RAD, CA, USA) and with monovalent antisera (Seiken, Niigata, Japan) and were also inoculated onto Kligler iron agar, semisolid sulfide indole motility medium, Falkow's broth containing lysine, and Andrade's peptone water containing mannitol for preliminary characterization. The organisms were differentiated by biotype on the basis of their ability to cause hemolysis of sheep red blood cells [5], sensitivity to polymyxin B [6], chicken blood cell agglutination [7] and sensitivity to group IV cholera phage [8]. Vibrio strains were stored at $-80{ }^{\circ} \mathrm{C}$ in Luria-Bertani (LB) broth supplemented with $30 \%$ glycerol.

\section{Preparation of Template DNA}

For screening of water sample for $V$. cholerae O1, DNA was extracted by the standard phenol-chloroform method from $10 \mathrm{ml}$ of primary culture before enrichment.

\section{PCR Amplification}

The primers used in this study are listed in Table 1. PCR was carried out in $0.2 \mathrm{ml}$ microcentrifuge tubes with $24 \mu \mathrm{l}$ of the PCR mixture containing $1 \mu 1$ each of forward and reverse primers $(20 \mathrm{pM} / \mu \mathrm{l})$ and $1 \mu \mathrm{l}(\mathrm{ca} .0 .1 \mu \mathrm{g})$ of template DNA

Table 1. Primers Used in this Study

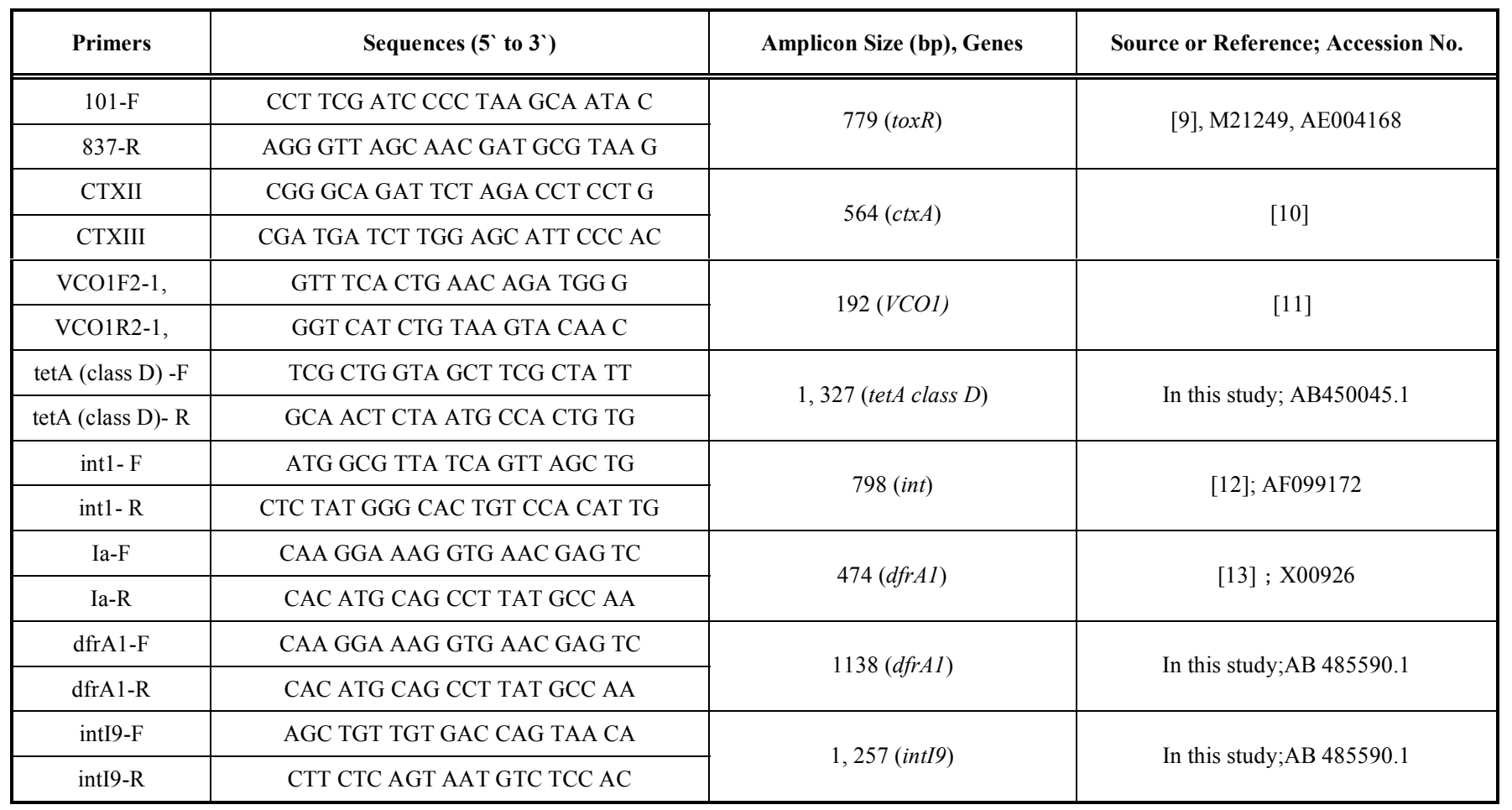


using Go-Taq Green Master Mix (Promega, Madison, Wis.). The solution was mixed, centrifuged briefly, and placed in an automated Eppendorf PCR Thermal Cycler (Hamburg, Germany). PCR amplification conditions were as follows: initial denaturation at $94^{\circ} \mathrm{C}$ for $2 \mathrm{~min}$, and 30 cycles of $1 \mathrm{~min}-$ denaturation at $94{ }^{\circ} \mathrm{C}, 1 \mathrm{~min}$-annealing at $60{ }^{\circ} \mathrm{C}$, and $1 \mathrm{~min}$ extension at $72^{\circ} \mathrm{C}$ with a final extension step at $72{ }^{\circ} \mathrm{C}$ for 7 min at the end of 30 cycles, followed by maintenance at 4 ${ }^{\circ} \mathrm{C}$. PCR products were separated by $2 \%$ agarose gel electrophoresis in 1xTAE buffer $(40 \mathrm{mM}$ Tris-acetate, $1 \mathrm{mM}$

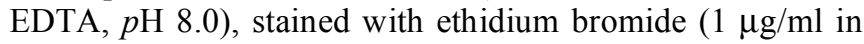
water), and visualized under UV light. The primers used in this study are shown in Table $\mathbf{1 .}$

\section{PFGE}

PFGE was performed as previously described by Albert et al. [14], with some modifications. In brief, several colonies of a test strain were collected by a sterile cotton swab and resuspended in $1 \mathrm{ml}$ of cell suspension buffer (CLS, $100 \mathrm{mM}$ Tris, $100 \mathrm{mM}$ EDTA, $\mathrm{pH}$ 8.0). The concentration of the cell suspension was adjusted to an optical density of $0.8-1.0$ at 610 $\mathrm{nm}$. An equal volume of bacterial suspension and 2\% SeaKem Gold agarose (Bio-Rad, Hercules, Calif) was prepared and dispensed into a plug mold. Bacterial cells were lysed with 25 $\mu l$ of proteinase $\mathrm{K}(20 \mathrm{mg} / \mathrm{ml})$ in $5 \mathrm{ml}$ of cell lysis buffer (CLB, $50 \mathrm{mM}$ Tris, $50 \mathrm{mM}$ EDTA, $\mathrm{pH} 8.0,1 \%$ Sarcosyl) at $54^{\circ} \mathrm{C}$ for 1 $\mathrm{h}$ and washed in TE buffer (10 mM Tris, $1 \mathrm{mM}$ EDTA, $\mathrm{pH}$ 8.0). Restriction digestion was performed with $20 \mathrm{UNotI}$ at $37^{\circ} \mathrm{C}$ for $4 \mathrm{~h}$. The agarose plug was stored in TE buffer at $4^{\circ} \mathrm{C}$. The restriction fragments were separated using the contour-clamped homogeneous electric field method on a CHEF-DRIII system (Bio-Rad) in 1\% pulsed-field-certified agarose in $0.5 \mathrm{x}$ TBE buffer. Electrophoresis was performed at $6 \mathrm{~V} / \mathrm{cm}$ at a temperature of $14^{\circ} \mathrm{C}$ with the following pulse times: 2 to $10 \mathrm{~s}$ $(13 \mathrm{~h})$ and 20 to $25 \mathrm{~s}(6 \mathrm{~h})$ at an angle of $120^{\circ}$. The gel was stained with ethidium bromide for $30 \mathrm{~min}$, destained, and photographed on a UV transilluminator. The DNA size standards used were a bacteriophage lambda ladder consisting of concatemers starting at $48.5 \mathrm{kbp}$ and increasing to $1,000 \mathrm{kbp}$ (Bio-Rad) and a Salmonella braenderup strain.

\section{Analysis of Drug-Resistance Gene Clusters}

The genetic organization of the gene cluster in SXT conjugative mobile element was determined essentially by primer walking referring to the sequence of $\mathrm{SXT}^{\mathrm{MO} 10}$ [15]. Amplified DNA was purified before sequencing using a Qiagen Gel Extraction kit (Qiagen, Hilden, Germany) and the nucleotide sequence was determined using a cycle sequencer with an AmplitaqFS Dye Terminator kit and an ABI PRISM 310 Genetic Analyzer (Applied Biosystems, PerkinElmer, Foster, CA, USA).

\section{RESULTS}

\section{Recovery of $V$. cholerae $O 1$ from Raw Vegetables and Dog Meat in a Market}

Strains of $V$. cholerae $\mathrm{O} 1$ were isolated from raw vegetable and dog meat samples collected on 6 January 2008 at Khuong Trung market in Hanoi. Two water samples from Nhue River (Duong Noi Commune) and one sample from a pond near a patient's house collected on 4 April 2008 were found to be positive for $V$. cholerae $\mathrm{O} 1$. One water sample collected from a pond in Phu Tho province on 7 April 2008 was found positive for $V$. cholerae $O 1$.

\section{Isolation of $V$. cholerae $O 1$ from Dogs in Slaughter Houses in Duongnoi and Dog Houses in Thanhhoa}

The delivery route of dogs imported from north-eastern provinces of Thailand is shown in Fig. (1). In Duong Noi Commune (Hanoi), 37 samples were collected from 4 slaughter houses on 8 May 2009 and 11 samples were found positive for $V$. cholerae $\mathrm{O} 1$. The positive samples were as follows: 1 rectal swab from a live dog, 1 rectal swab from a slaughtered dog, 2 from knives, 4 from dog-meat, 2 from water samples in the buckets to wash dog-meat, 1 from the floor surface in a slaughter house. On 13 May 2009, 54 samples were collected in dog houses in Thanh Hoa province and 3 samples were found to be positive for $V$. cholerae $\mathrm{O} 1$ (two rectal swabs from dogs and one bowl containing drinking water for dogs). After one week on 20 May 2009, more than 300 rectal swabs from imported dogs were examined at the Centre for Preventional Medicine, Thanhhoa. All samples were negative for $V$. cholerae $\mathrm{O} 1$.

\section{Screening of the Samples from Dogs and Environmental Water Samples for $V$. cholerae 01 with Cholera Toxin $(\operatorname{ctx} A)$ Gene}

Before the isolation of $V$. cholerae O1, DNA was extracted from the primary culture of water samples and rectal swabs from dogs and used as template DNA for multiplex PCR using primers for toxR, ctxA and $V C O 1$ genes (Fig. 2). Three water samples and $4 \operatorname{dog}$ rectal swab samples showed positive for $V$. cholerae $\mathrm{O} 1$ with $\operatorname{ctx} A$ gene. One environmental water sample (lane 4 in Fig. 2) and a rectal swab from a dog showed the presence of non-O1 vibrios.

\section{Clonality of Epidemic Strains Isolated between 2007 and 2009 in Vietnam}

The gene tetA (class D) encoding resistance to tetracycline was first identified in $V$. cholerae $\mathrm{O} 1$ strain $\mathrm{HN} 1$ isolated in 2007 in Hanoi (accession no:AB450045.1). This new gene may work as a marker for the epidemiological study on cholera. When characterized by multiplex PCR using primers for tetA (class D), int and $d$ frAl genes of the SXT mobile element, the same clonality was observed among strains isolated from different sources between 2007 and 2009 in northern Vietnam (Fig. 3).

\section{Clonality of Epidemic Strains in Laos, Thailand and Vietnam During 2007 and 2009}

Four strains of $V$. cholerae $\mathrm{O} 1$ ( 2 isolates from 2007 and 2 isolates from 2008) and 12 DNA extracts of $V$. cholerae O1 (4 each year from 2007 through 2009) were provided by the Center for Laboratory and Epidemiology, Laos and by National Institute of Health, Thailand. When characterized by multiplex PCR by using primers for $d f r A 1$, tetA (class D) and intI9 genes, the same clonality was shown among isolates in Laos and Vietnam (Fig. 4). Furthermore, when characterized by single PCR using primers for tetA (class D) and $d$ frAl genes, the same clonality was observed among isolates in Thailand and Vietnam (Fig. 5). These data suggest that the epidemic clones in Laos, Vietnam and Thailand between 2007 and 2009 are the same. 


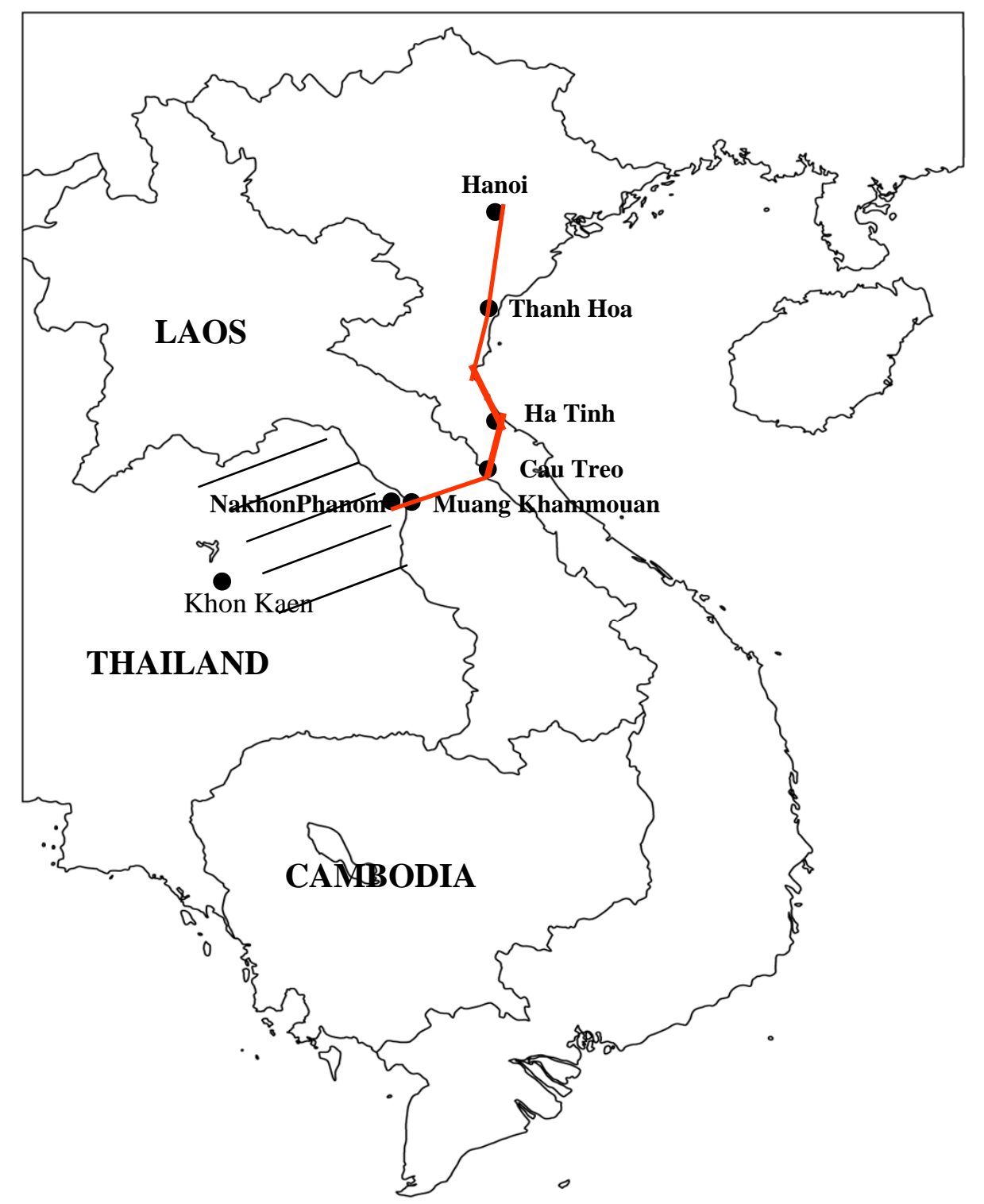

Fig. (1). The delivery route of dogs imported from north-eastern Thailand.

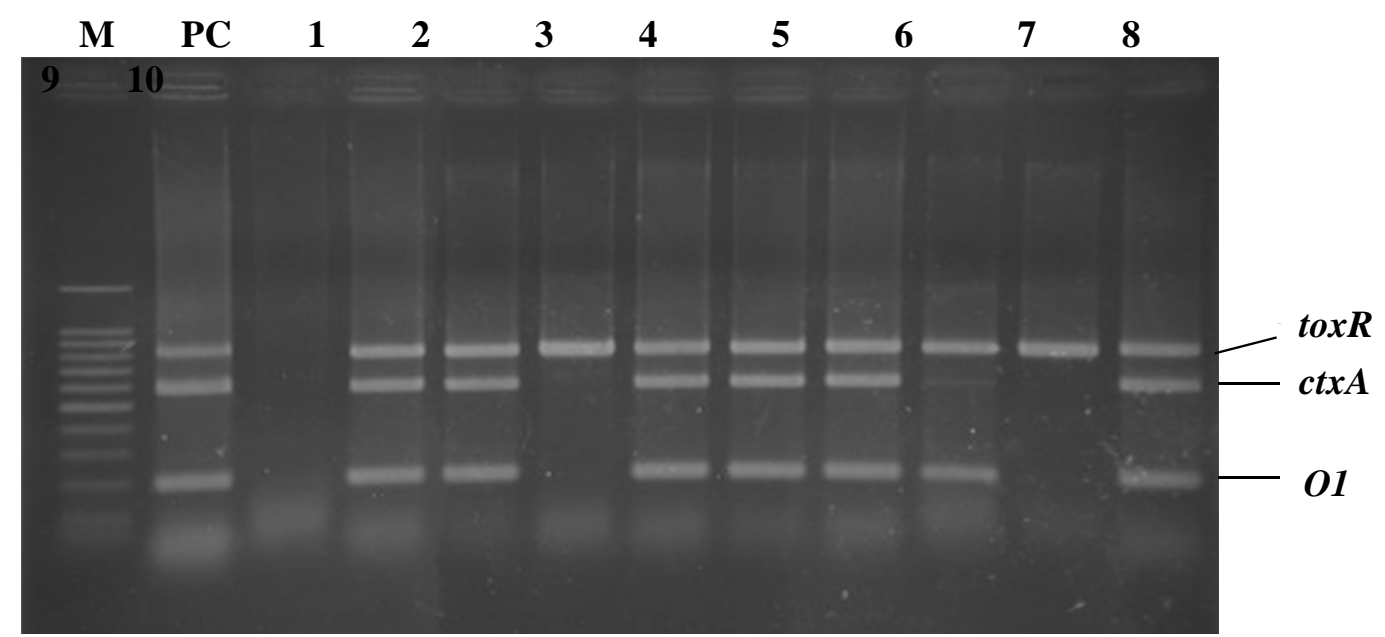

Fig. (2). Multiplex PCR to detect toxR, O1, and ctxA genes in water, and dog samples in Hanoi and Thanhhoa in May, 2009. Lanes M: 100 bp ladder PC: positive control (strain HN1isolated in Hanoi in 2007): lanes 1-5: environmental water samples collected from water sources near slaughter houses in Duongnoi (Hanoi) : 6, 7: Dog-rectal swabs from Duongnoi: lanes 8-10: dog-rectal swabs from Thanhhoa. Template DNAs were extracted from primary cultures before isolation of $V$. cholerae $\mathrm{O} 1$. 


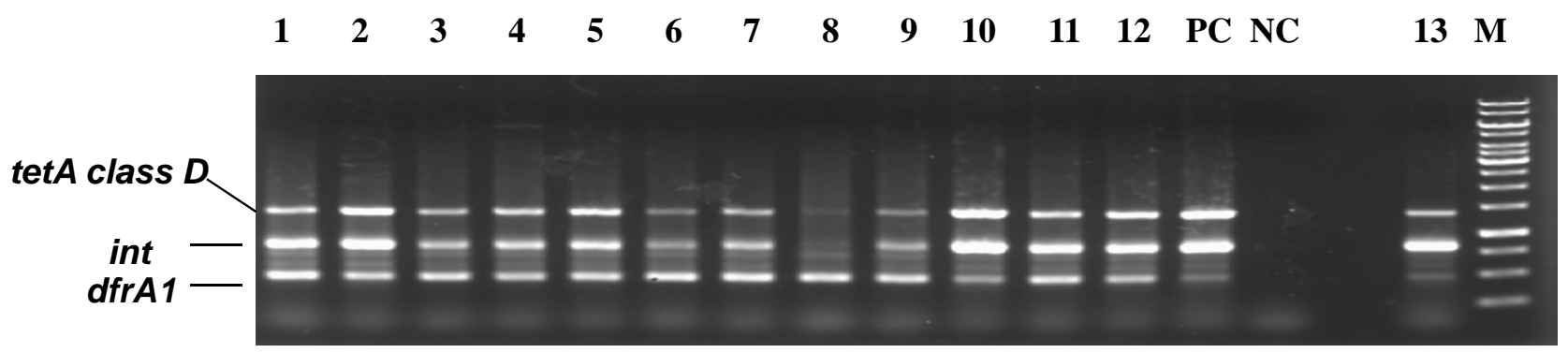

Fig. (3). Detection of tetA (class D), int, and $\operatorname{dfrA1}$ genes in $V$. cholerae $\mathrm{O} 1$ strains from dogs, slaughterhouses (SH) and its environment in Hanoi in May, 2009. Lane 1: floor in a slaughter house: lane 2; dog (killed), 3; dog (live with diarrhea), lane 4: knife, lane 5: dog (killed), lanes 6, 7: water to wash dog meat: lane 8: dog meat: lane 9: dog (live) lane 10: equipment in a slaughter house lane 11; dog meat, 12; Nhue River (1 km away from SH), PC: positive control (HN1), NC: negative control, 13; cholera patient's stool (Thanhhoa), M: 1k bp ladder.

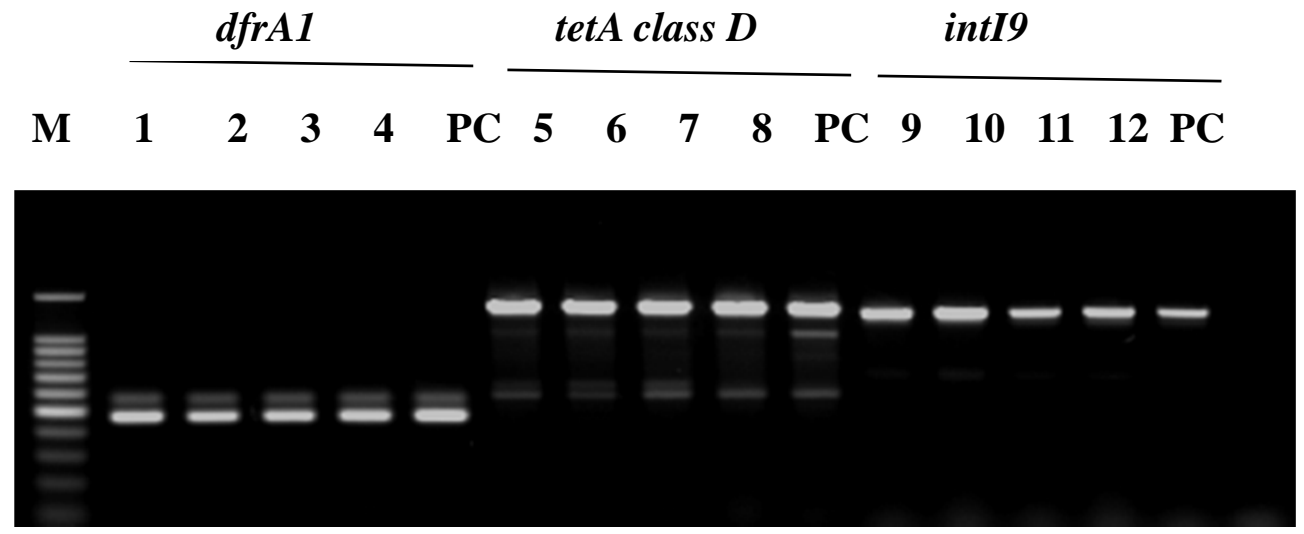

Fig. (4). Single PCR to detect antibiotic resistance genes of $\boldsymbol{V}$. cholerae $\mathrm{O1}$ isolates in Laos in 2007-2008. Lanes: M; 100 bp ladder, 1,2, $5,6,9,10 ; 2007$ - isolates, $3,4,7,8,11,12 ; 2008$-isolates, PC ; positive control (HN1)
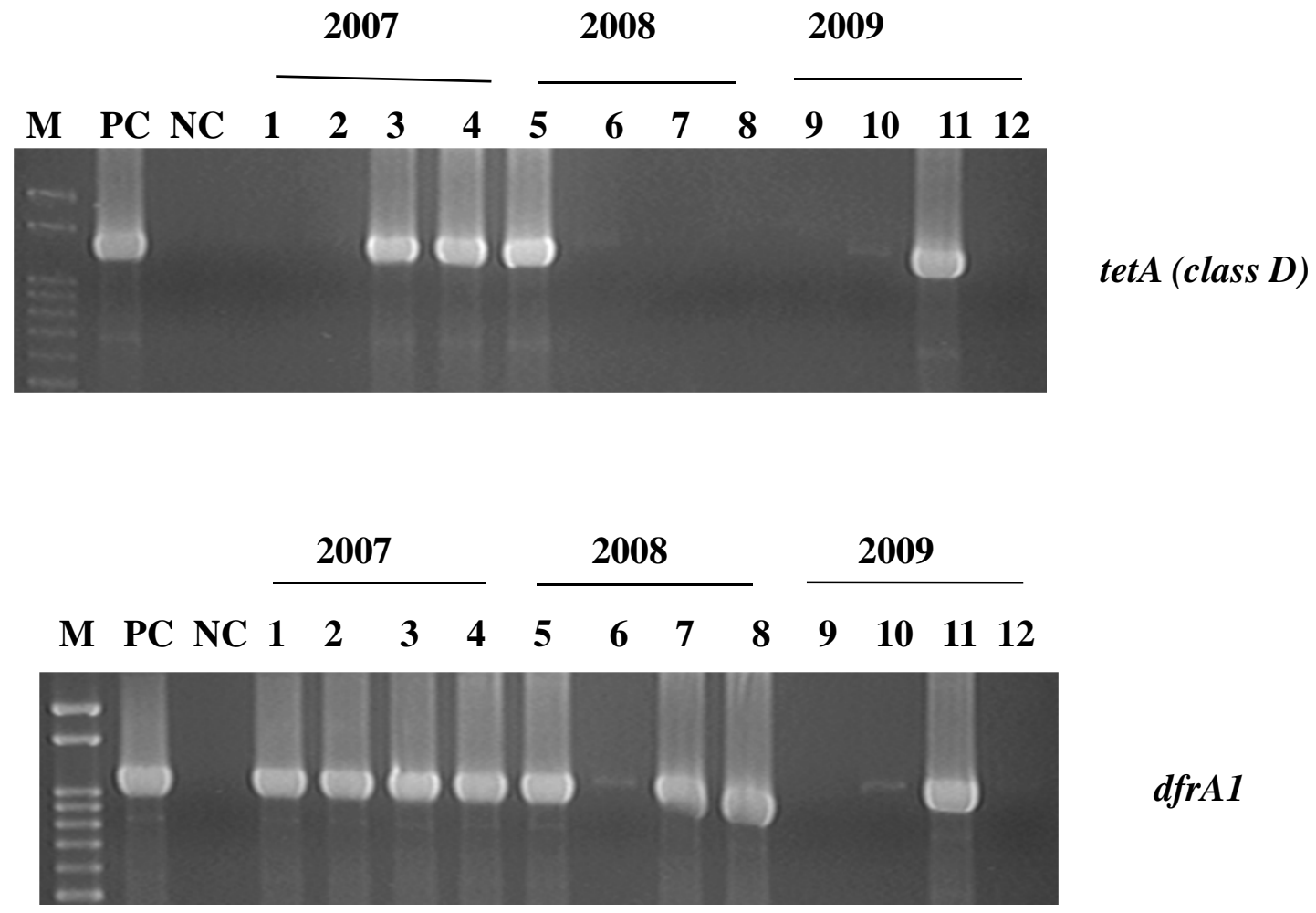

Fig. (5). Detection of $t e t \boldsymbol{A}$ (class D) and $\boldsymbol{d f r} \boldsymbol{A l}$ genes in Thailand isolates of $\boldsymbol{V}$. cholerae $\mathrm{O1}$ between 2007and 2009. Lanes: M; 100 bp marker DNA: PC: positive control (strain HN1): lanes 1-10:Thailand isolates:VC49/50, VC54/50, VC170/50, VC440/50, VC26/51, $\mathrm{VC} 52 / 51, \mathrm{VC} / 59 / 51, \mathrm{VC} 126 / 51, \mathrm{VC} 1 / 52, \mathrm{VC} 2 / 52, \mathrm{VC} 3 / 52, \mathrm{VC} 9 / 52$, respectively. 


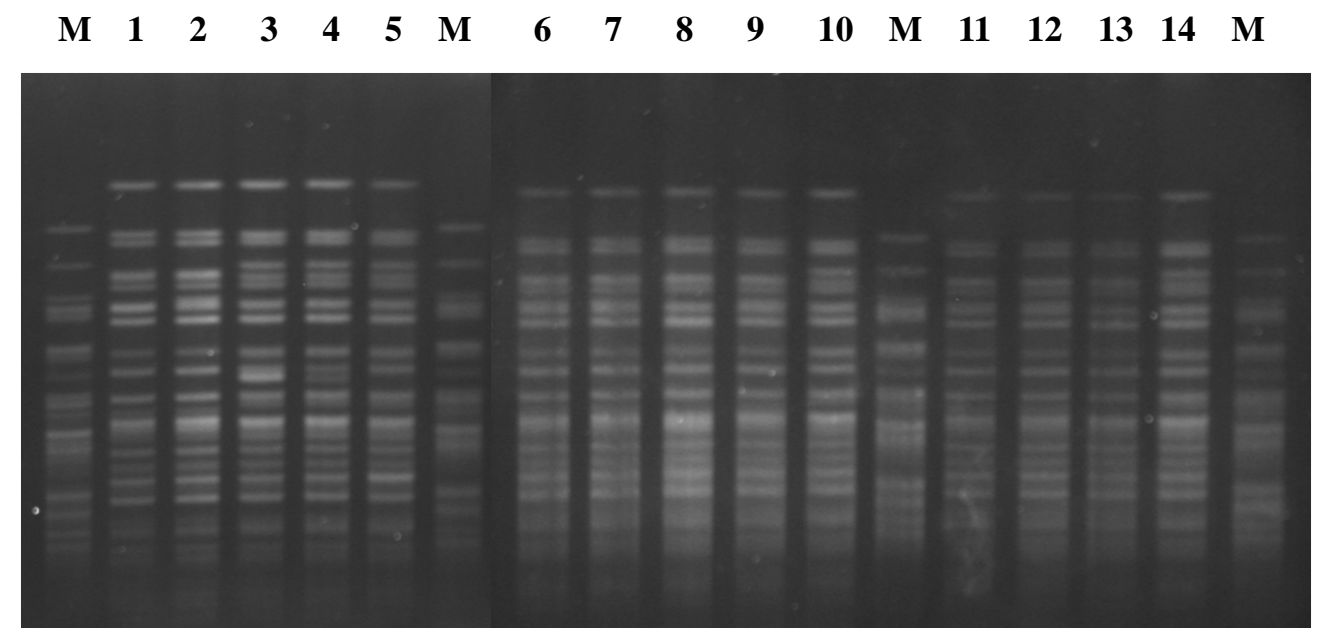

Fig. (6a). PFGE of Not $\mathbf{I}$ restriction digests of $\boldsymbol{V}$. cholerae 01 isolates in Vietnam between 1995 and 2008. Lanes: M; Salmonella braenderup as a control, lanes 1 to 14; (strain no. isolation year);55. 2004, 73. 2004, 55. 2007, 550. 2007, 1692. 2008, 07. 1995, 32. 2002, 272. 2003, 84. 2004, 01. 2007,12. 2002, 307. 2003, 43. 2004, 17. 2008, respectively.

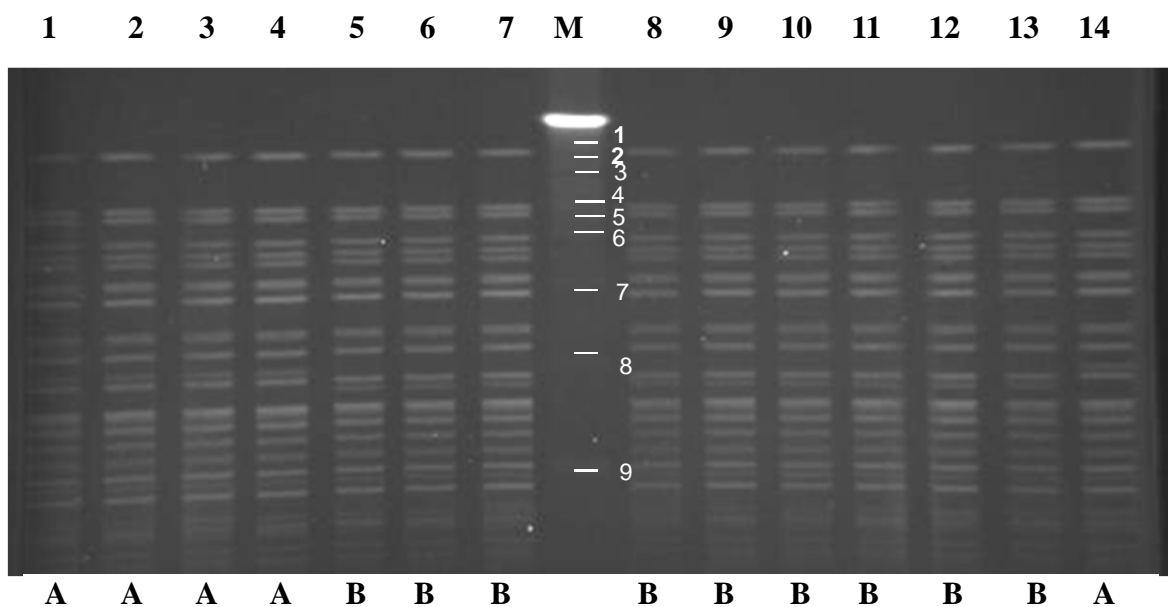

Fig. (6b). PFGE analysis of $\boldsymbol{V}$. cholerae $\mathrm{O} 1$ isolates in 2010 in southern provinces of Vietnam. Lanes: M; marker DNA, 1 to 14; (strain no.-province); 01-AG, 115-AG, 496-BP, 43-SG, 673-AG, 21-TP, 317-TN, 232-ND, 354-BT. 672-CT,684-CM, 586 TG, 662-BL, 781-BL. Bands1, 2, 3, 4, 5, 6, 7, 8, and 9 are 438.5, 388.0, 339.5, 291.0, 242.5, 194.0, 145.5, 97.0, and 48.5 kb, respectively. Abbreviation of province name: AG; Angiang, TP; Ho Chi Minh City, TN; Tayninh, ND; Namdinh, BT; Bentre, CT; Cantho, CM; Camau, TG; Tiengiang, BL; Baclieu.

\section{PFGE}

One $V$. cholerae $\mathrm{O} 1$ isolate from 1995, 2 isolates from 2002 and 2003, 4 isolates from 2004, 3 isolates from 2007 and 2 isolates from 2008 were analyzed by PFGE after NotI restriction enzyme digestion. Of the 14 tested, 9 isolates from 1995 to 2004 produced similar patterns that differed from the isolates from 2007 to 2008 (Fig. 6a). Of the 13 isolates from 2010 in the southern provinces of Vietnam, two patterns, designated A and B were seen (Fig. 6b). Three samples from Angian province (lanes: 1, 2 and 5 in Fig. 6b) were obtained from Cambodian citizens who came to Angian for treatment of acute diarrhea. One strain isolated in Nam Dinh (a northern province) in 2009 produced pattern B.

\section{Nucleotide Sequence Accession Number}

The DNA sequence described in this article has been deposited in the DDBJ database under accession numbers AB450045.1 and AB485590.1.

\section{DISCUSSION}

As hypothesized earlier by Sack (3), dogs from cholera endemic areas caused the transmission of the infection in northern Vietnam. Between 1 January and 31 October 2007, there were 600 cases of cholera spread across 36 provinces in Thailand [16]. In Laos, in December 2007, cholera cases started to be reported in Sekong province with the index case being reported on 19 December. As of 19 January 2008, a total of 362 cases were registered including 3 deaths in 32 villages located in 2 districts of the province: Thateng and Lamam [17]. Acute diarrhea spread to 14 localities in Vietnam's northern and central regions, affecting 1,907 people from 23 October 2007 to 31 December 2007 [18] The 14 affected provinces included the capital city, Hanoi, and surrounding provinces. Hanoi had seen the largest number of acute diarrhea cases... At the beginning of the outbreak, no one suspected dogs as the vehicle of cholera transmission. The common food taken by patients was the shrimp paste, 
because shrimp paste is always served as a sauce for dog meat.

At the end of December 2007, we collected samples from dog meat, table, floor, knife and water at slaughter houses in Duc Giang Commune, Hoai Duc District, Hanoi, but were unable to detect $V$. cholerae O1. Rectal swabs and the other swabs to collect samples were carried in test tubes with screw cap containing alkaline peptone water, it seemed there was no marked difference between rectal swab and conventional stool culture. Ponds near patients' houses were easily contaminated with the epidemic strain from human stools. Data from interviews with cholera patients conducted during the first 2 weeks of the epidemics shows that $64-83 \%$ of the patients ate dog meat. An investigation of slaughter houses was conducted in Hanoi in May 2009 to collect rectal swabs from dogs, and water samples in buckets used for washing dog meat. We found several samples positive for $V$. cholerae $\mathrm{O} 1$. This is the first report of cholera transmission possibly caused by dogs imported from cholera endemic areas of neighboring countries. So far there is no report on the isolation of epidemic strain of $V$. cholerae $\mathrm{O} 1$ with $c t x A$ gene from dogs. These dogs were imported from the north eastern province of Thailand, where cholera was endemic $[19,20]$.

The first isolate of $V$. cholerae $\mathrm{O} 1$ in Hanoi (HN1) in 2007 was analyzed genetically to characterize its properties. We found tet $A$ (class D) in the conjugative mobile element (SXT element) which carries multiple drug resistance genes. The gene, tetA (class D) was first reported in a Spanish isolate of Photobacterium damsalae subsp. piscicida by Osorio CR, et al. [21], this gene was never reported previously in isolates of $V$. cholerae $\mathrm{O} 1$. Therefore we used the tetA (class D) gene as a marker to discriminate strains isolated in Laos, Vietnam and Thailand together with the other genes (dfrA1, int, and intI9). In northern Vietnam including Hanoi, fresh dog meat is prepared in Hanoi from dogs imported across the border with Laos. These imported dogs are gathered in dog houses in Thanh Hoa province and then transferred to Hanoi. Since we isolated $V$. cholerae $\mathrm{O} 1$ from the rectal swabs of 2 dogs from slaughter houses in Hanoi, we went to Thanh Hoa province to collect samples from dogs and from the environment around dog houses. Two rectal swabs from dogs and one drinking water sample were found to be positive for $V$. cholerae $\mathrm{O} 1$. The isolates of $V$. cholerae $\mathrm{O} 1$ from patients, imported dogs and environmental water sources collected from 2007 to 2009 were found to be the same clone as those isolates from Laos and Thailand, when judged by PCR and PFGE.

The results of PCR for Thailand isolates showed discrepancies because of the template DNA. The template DNA was prepared by the supernatant of heat-treated whole cells. Current epidemic strains in Vietnam seem to be different from those isolated before 2007. Therefore, they were probably introduced into Vietnam in 2007. Although the route of cholera transmission seemed to differ between North and South Vietnam, the same clone was seen among the isolates from 2007 to 2010. A minor difference observed in PFGE profile between isolates in 2010 from the southern provinces may be derived from some mobile elements such as SXT element and integrated filamentous phage genes. Furthermore, currently epidemic El Tor strains in Thailand
[19], Laos [22], and Vietnam [23] carry ctx $B^{\mathrm{Cl}}$ (El Tor variant). The results of multiplex PCR and PFGE $[19,22]$ suggested that the same epidemic clone is spread widely in Southeast Asian countries. The PFGE profile suggested that three Cambodian strains seemed to be the same clone with those isolated in Vietnam. Multilocus sequencing typing (MLST) was reported to have better discriminatory ability for typing $V$. cholerae than does pulse-field gel electrophoresis [24], and multi-virulence locus sequencing typing (MVLST) was reported to be more discriminatory than MLST [25]. Although, we used a new gene (tetA class $D)$ as a specific marker for the epidemiological study on cholera, new methods such as LAMP in rectal swab could improve detection of $V$. cholerae $\mathrm{O} 1$.

In Vietnam, people never eat dog meat for 2 or 3 days at the beginning of every lunar month,. because they believe that eating dog meat at the beginning of the month is inauspicious. This custom reflects the low incidence of acute diarrhea in the first two weeks of the lunar calendar (data not shown). Not all the dogs imported were necessarily infected with $V$. cholerae $\mathrm{O} 1$; some dogs in some batches were infected. A review of importation practices of animals from cholera-endemic regions may be required to prevent future transmission.

\section{CONFLICT OF INTEREST}

The authors have no conflicts of interest to report.

\section{ACKNOWLEDGEMENT}

We acknowledge the financial support from the Ministry of Science and Technology, Vietnam. We are grateful to the National Institute of Health, Ministry of Public Health, Thailand and to the Center for Laboratory and Epidemiology, Lao PDR for providing us the extracted DNA and the strains of $V$. cholerae $\mathrm{O} 1$. We are grateful to the Japan Society for the Promotion of Science (CORE UNIVERSITY PROGRAM) and Global COE Program of Ministry of Education, Culture, Sport, Science and Technology of Japan for supporting this study. This work was also supported by the Program of Japan Initiative for Global Research Network on Infectious Diseases ( J-GRID, MEXT, Japan. We thank Professor MJ Albert, Kuwait University, Kuwait for his critical review of the manuscript.

\section{REFERENCES}

[1] Abou-Gareeb AH. On the search of vibrios in the cattle dung at Calcutta and a Bengal village during the inter-epidemic period of the years 1958-1959. Int J Prophyl Med Soc Hyg 1960; 4:12-3.

[2] Saad A, Gordon RS. Vibrio infections of ruminants. Cholera Research Laboratory Annual Report Dacca 1964.

[3] Sack R B. A search for canine carriers of Vibrio. J Infect Dis 1973; 127: 709-12.

[4] Sanyal SC, Singh SJ, Tiwari IC, et al. Role of household animals in maintenance of cholera infection in a community. J Infect Dis 1974; 130: 575-9.

[5] Sanyal SC, Sen D, Sil J, Mukerjee S. Differentiation of cholera and El Tor vibrios. Indian Council of Medical Research Technical Report Series 1971; 9: 194-7.

[6] Roy C, Mridha K, Mukerjee. Action of polymyxin on cholera vibrios. Techniques of determination of polymyxin sensitivity. Proc Soc Exp Biol Med 1965; 119: 893-6.

[7] Finkelstein RA, Mukerjee S. Haemagglutination: a rapid method for differentiating Vibrio cholerae and El Tor vibrios. Proc Soc Exp Biol Med 1963; 112: 355-9.

[8] Mukerjee S. The bacteriophage susceptibility test in differentiating Vibrio cholerae and Vibrio El Tor. Bull WHO 1963; 28: 333-6. 
[9] Rivera IN, Chun J, Huq A, Sack RB, Colwel RR. Genotype associated with virulence in environmental isolates of Vibrio cholerae. Appl Environ Microbiol 2001; 67: 2421-9.

[10] Fields PI, Popovic T, Wachsmuth K, Olsvic O. Use of polymerase chain reaction for detection of toxigenic Vibrio cholerae O1 strains from the Latin America cholera epidemics. J Clin Microbiol 1992; 30: 2128-1.

[11] Islam MM, Kabir MG, Moly PK, Islam AFMT, Rakib MA. Detection of Vibrio cholerae O1 and O139 serogroups directly from stool specimens by combined immunomagnetic separation and polymerase chain reaction. Pakistan J Biol Sci 2004; 7: 1654-9.

[12] Hochhut B, Waldor MK. Site-specific integration of the conjugative Vibrio cholerae SXT element into prfC. Mol Micrbiol 1999.; 32: 99-110.

[13] Navia MM, Ruiz J, Sanchez-Cespedes J, Vila J. Detection of dihydrofolate reductase genes by PCR and RFLP. Diag Microbiol Infect Dis 2003; 46: 295-8.

[14] Albert MJ, Bhuiyan NA, Talukder KA, et al. Phenotypic and genotypic changes in V. cholerae O139 Bengal. J Clin Microbiol 1997; 35: 2588-92.

[15] Hochhut B, Lotfi Y, Mazel D, et al. Molecular analysis of antibiotic resistance gene clusters in Vibrio cholerae $\mathrm{O} 139$ and $\mathrm{O} 1$ SXT constins. Antimicrob Agents Chemother 2001; 45: 29913000 .

[16] ProMed. PRO/EDR > Cholera, Diarrhea and Dysentery Update 2007; 55: Archive Number 2007 1107.3620.

[17] WHO. Global Task Force on Cholera Control. Cholera Country Profile: Laos 2008.
[18] Minstry of Health. Yearly report on communicable disease surveillance in Vietnam, Vietnam

[19] Okada K, Chantaroj S, Roobthaisong A, Hamada S, Sawanpanyalert P. Short Report: A cholera outbreak of the Vibrio cholerae $\mathrm{O} 1 \mathrm{El}$ Tor variant carrying $c t x \mathrm{~B}$ in northeastern Thailand in 2007. Am J Trop Med Hyg 2010; 82: 875-8.

[20] Winn P. The dog meat mafia. GlobalPost.com, 2009. available from: http://www.all-creatures.org/article/ar-dogmeat01.html

[21] Osorio CR, Marrero J, Wozniak RA, et al. Genomic and functional analysis of ICEPda Spa1, a fish-pathogen-derived SXT-related integrating conjugative element that can mobilize a virulence plasmid. J Bacteriol 2008; 190: 3353-61.

[22] Sithivong N, Izumiya $\mathrm{H}$, Munnalath $\mathrm{K}$, et al. Cholera outbreak, Laos, 2007[letter]. 2010 Apr. Available from http://www.cdc.gov/EID/content/16/4/745.htm

[23] Nguyen BM, Lee JH, NgoTC, et al. Cholera outbreaks caused by an altered Vibrio cholerae O1 El tor biotype strain producing classical cholera toxin B in Vietnam in 2007 to 2008. J Clin Microbiol 2009; 47: 1568-71.

[24] Kotetishvili M, Stine OC, Chen Y, et al. Multilocus sequence typing has better discriminatory ability for typing Vibrio cholerae than does pulsed-field gel electrophoresis and provides a measure of phylogenetic relatedness. J Clin Microbiol 2003; 41: 2191-6.

[25] Teh CS, Chua KH, Thong KL. Genetic variation analysis of Vibrio cholerae using multilocus sequencing typing and multi-virulence locus sequencing typing. Infect Genet Evol 2011; 11: 1121-8.

(C) Ngo et al.; Licensee Bentham Open.

This is an open access article licensed under the terms of the Creative Commons Attribution Non-Commercial License (http://creativecommons.org/licenses/ by-nc/3.0/) which permits unrestricted, non-commercial use, distribution and reproduction in any medium, provided the work is properly cited. 